\title{
Water Absorption Process Parametric Selection For Natural Composites Using The PROMETHEE Method And Analytical Hierarchy Process For Objective Weights For Ship's Hull Application
}

\author{
Victor Chidiebere Maduekwe ${ }^{1}$, Sunday Ayoola Oke ${ }^{2}$
}

(Received: 01 October 2020 / Revised: 10 September 2020 / Accepted: 10 December 2020)

\begin{abstract}
- the purpose of this study is to establish the importance of parameters in a water absorption process for natural particulate composite for ship's hull applications. To attain useful and reliable outcomes, the subjective evaluation of the assessor and weights of inputs are combined in a PROMETHEE and analytical hierarchy process (AHP) approach. The PROMETHEE serves the goal of ranking while the AHP is deployed to establish the objective weighing. It was found that time is the heading parameter for the natural particulate thermoset composite solutions, compared with thickness and length. By integrating PROMETHEE and AHP, it was proved that this approach offers a higher level of confidence to composite developers than initiative practices that currently dominate choices of parameters. It is particularly useful for natural particulate water absorption parametric selection since it is an innovative and scientific choice approach involving multicriteria analysis.
\end{abstract}

Keywords - composites, multicriteria, process parameters, PROMETHEE, water absorption.

\section{INTRODUCTION}

$\mathrm{N}$ atural particulate reinforced polymer (NPP) composites are thermoset composite materials comprising of powdered natural materials that are integrated with epoxy resins for composite development [1]. NPP composites exhibit outstanding properties of being renewable, lightweight, low cost and environmentally friendly. These attributes are desired in many marine applications such as boats and ships. The central idea of water absorption studies in composite fabrication is to ascertain the structural integrity of natural polymer composites in on-gong or postexperimental observations [2-7]. Usually, all important properties of the polymer composites are tested to ascertain how they are affected by water absorption [34], [6]. A pocket of tests may include a water absorption test, tribo performance, mechanical, electromagnetic interference and metallurgical behaviour of water invaded composites [2-8]. Their worn surfaces wear mechanisms and wear debris are also studied using the scanning electron microscope morphology. Additional studies may include post-water invasion wear effect studies through the variation of applied load, sliding time and percentage of reinforcements that the polymer composite contains. However, the selection of the best parameters of the polymer composite regarding the water absorption process is desirable to achieve the utmost structural integrity of the polymer composite.

[9] studied composite material selection regarding natural fibre. They focused on seven product design

Victor Chidiebere Maduekwe is with Department of Mechanical Engineering, University of Lagos, Lagos, Nigeria. E-mail: sa_oke@yahoo.com

Sunday Ayoola Oke is with Department of Mechanical Engineering, University of Lagos, Lagos, Nigeria. E-mail: sa_oke@yahoo.com criteria that were assessed by ten experts. The outcome revealed that analytical hierarchy process and VIKOR are complementary tools with the choice of kenaf as the best natural fibre in the side-door application. [10] applied fuzzy VIKOR to identify essential natural fibre in fibre metal laminate for car format's hood. The result places kenaf as the best material. [11] deployed TOPSIS and multi-attribute utility theory to evaluate composites with optimum properties. The outcome was that $20 \%$ nano boron nitride nanocomposites are tagged as the material with the best properties. [1] deployed preference selection index approach to priorities and optimise the properties of ceramics particulate $(\mathrm{SiO} / \mathrm{SiC})$ fortified AA2024 alloy composite. Aluminium alloy composite was with the same content of ceramics was the best in properties.

[5] developed on hybrid polypropylene composites and tested changes in water absorption capacity of various compositions and particle sizes of the composite. It was concluded that the 53-micrometre composite. [7] studied the water absorption characteristics of woven fan palm fibres-fortified composites as changes in silane, alkali and their combinations are imposed on the system. [6] examined water absorption in the mechanical properties of treated plantain composites. A reduced tensile and flexural strength of the composites was observed due to water advancement through the fibre matrix interaction and the extended water-immersion cycle. [12] analysed the mechanical characteristics of combines epoxy polymer matrices fortified with glass and jute fibers. [13] studied the influence of water absorption on the mechanical attributes of natural fibre composite Saxena and [14] characterized hybrid wood composites to analyse the influence on the water on them and interactions with mechanical properties.

While designing and developing composites, the composite designer and the fabrication engineer use a system of initiation of the best guess of values to estimate the time it may take composites being 
developed to expire in its service life when subjected to water-invaded conditions. Other parameters such as the likely final weight of the composite, its thickness and final composite's length are determined similarly. This condition indicates a huge gap between design and fabrication practices in engineering design and manufacturing and literature records. Consequently, a precise and detailed appraisal of various parameters involved in the water absorption process is necessary to guide practitioners in making the most suitable parametric selection in a clear and transparent dimension. From one side, this work strives to lower the research gap and enrich the scientific resources pertaining the rational monitoring and control of composite design and fabrication resources. From the other side, the work targets to appraise the parameters of the water absorption process. This appraisal is achieved using PROMETHEE (Preference Ranking Organization Method for Enrichment and Evaluations). To concur with [15], the choice of PROMETHEE may be made as it demonstrates unrivalled success to solve problems. This is done consistent with the views of [16-21].

PROMETHEE is increasingly being established as a reliable method in engineering practice. It is multicriteria to solve problems based on organized linkage of assumptions, pairwise comparison, preference degree, multicriteria preference degree, multi-criteria preference flow, uni-criterion net-flow and promethee preference functions. Created in 1982 by Burns, and refined in 1985 when Vincke worked with Maschal in 1994, the tool provides excellent advantages compared with intuition and experience of the designer and fabrication engineer. Reliable results have been reported by authors in different areas (Table 1). [22] declared high reliable outcomes by using PROMETHEE to analyse eight composite materials towards achieving optimum design. [23] elevated the rehabilitee of PROMETHEE in electrical discharge machining of A17075/SiC/WS2, composite as it produced good results.

TABLE 1.

PAPERS DISCUSSING PROMETHEE-ORIENTED STUDIES

\begin{tabular}{|c|c|c|c|c|}
\hline S/No. & $\begin{array}{l}\text { Research } \\
\text { aspect/Industry } \\
\text { focus }\end{array}$ & Author(s) & Article's thesis & Key terms describing contents \\
\hline 1 & 3D printing & {$[24]$} & $\begin{array}{l}\text { Employed analytic } \\
\text { hierarchy process to select } \\
\text { low-cost 3D printers }\end{array}$ & $\begin{array}{l}\text { Additive manufacturing, decision- } \\
\text { making method, quantitative } \\
\text { evaluation, benchmarking }\end{array}$ \\
\hline 2 & Municipal services & {$[25]$} & $\begin{array}{l}\text { Used fuzzy multicriteria } \\
\text { decision making approaches } \\
\text { for effective assignment of } \\
\text { municipal services }\end{array}$ & $\begin{array}{l}\text { Municipal service selection, multi- } \\
\text { criteria decision making, fuzzy } \\
\text { TOPSIS, fuzzy AHP }\end{array}$ \\
\hline 3 & Cryptography & {$[26]$} & $\begin{array}{l}\text { Developed a procedure to } \\
\text { evaluate different } \\
\text { performance parameters and } \\
\text { ranked the created fuzzy } \\
\text { values using PROMETHEE }\end{array}$ & $\begin{array}{l}\text { Data encryption, fuzzy logic, } \\
\text { PROMETHEE, smart choice, } \\
\text { cryptography }\end{array}$ \\
\hline 4 & Flood mitigation & [27] & 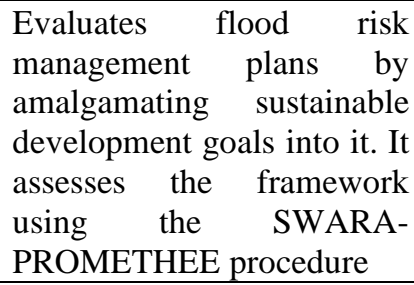 & $\begin{array}{l}\text { Decision support, flood mitigation, } \\
\text { flood management, risk } \\
\text { management, sustainable } \\
\text { development, sustainability }\end{array}$ \\
\hline 5 & Turning operation & {$[28]$} & $\begin{array}{l}\text { Studies the usefulness of } \\
\text { graphene rooted nanofluids } \\
\text { while turning D3 tool steel } \\
\text { using the least quantity of } \\
\text { lubrication and uses } \\
\text { PROMETHEE to establish } \\
\text { the vital factors influencing } \\
\text { the response }\end{array}$ & $\begin{array}{l}\text { Graphene, nanofluids turning, } \\
\text { surface roughness }\end{array}$ \\
\hline 6 & Smart industries & [29] & $\begin{array}{l}\text { Acknowledge the utility of } \\
\text { PROMETHEE as a valuable } \\
\text { procedure to attain } \\
\text { improvement in system } \\
\text { analysis in its literature } \\
\text { review }\end{array}$ & $\begin{array}{l}\text { Industry } 4.0, \quad \text { multi-criteria } \\
\text { decision making, smart factory, } \\
\text { fuzzy TOPSIS, fuzzy AHP }\end{array}$ \\
\hline
\end{tabular}

[8] declared merits in using PROMETHEE to rank composite involving bronze fibres and phenolic resin in wear and frictional experiments. Additional studies that demonstrated good rehabilitee of PROMETHEE as a method could be found in [30] concerning property 
comparison in heat-treated wood-propylene composites. [31] deployed fuzzy PROMETHEE to choose materials for an instrument panel in an automobile. [32] applied PROMETHEE in a study to reinforce A16061 with zirconia, zirconia + aluminium oxide and fused zirconia aluminium. [4] examined corn husk fibre reinforced composite and how the composition of the filter impacts on the mechanical properties of the composite. It was concluded that water absorption capacity is directly dependent on the samples' density. [3] examined the influence of over-ply on moisture absorption attribute of a composite laminate. Over-ply was rated as an efficient agent to decelerate moisture absorption in the composite. It was found also to hold up the equilibrium moisture absorption time.

Presently, there is no study found to have combined PROMETHEE and AHP in water absorption process parametric selection for natural particulate composites for ship's hull. In the multicriteria decision-making arena, the weights of criteria are achieved from experts. These experts often assign unequal weights to criteria according to their diverse opinions have been captured in AHP. From a broad review of literature by [33] and concurrence by [15], it is known that the original design of PROMETHEE method fails to declare how criteria weights are determined. Scholars have over the years adopted convenient weight determining methods [33], [15]. Thus, in this study, a robust and adequate weight evaluation tool is adopted. A robust class of weight determining method is the analytical hierarchy process, which operates on importance rating, guided by a scale of importance with which experts offer their judgements based on their experience and technical competence on the subject of study. In this work, the analytical hierarchy process was chosen as opposed to competing methods such as entropy weights and the surrogate weight determining method in the literature. Although [34] proposed enhancement of the AHP method, the authors still declared the inherent advantages of the method. As AHP is extremely reliable and flexible to desirable measurement levels, capable of establishing weights in decisions, the adoption of AHP for this ship's hull application may enhance the likelihood of the composite product's success as the establishment of weights for the key parameters promises to produce more reliable and accurate results in decisions ([35]). Consequently, this work exploits the integration of PROMETHEE and AHP with synergic benefits, to choose appropriate water absorption parameters for natural particulate composites in ship's hull applications. By the PROMETHEE approach, the water absorption parameters to be chosen are labelled as initial weight (A), final weight (B), length (C), thickness (D) and time (E). It is essential to establish the time of water absorption of the natural particulate composite for fabrication purpose as the ship's hull could resist water in a limited time and time dictates the structural integrity of the composite. The initial weight of the ship's hull is an essential attribute since the floating ability of the ship depends on it. The final weight of the ship's hull is also necessary to determine the floating attributes of the composite. The length of the ship's hull is also important as too much length brings excessive product cost. The thickness of the ship's hull is essential to determine the area to be occupied by the composite.

Consequently, to avoid failure as the composites are manufactured for the ship's hull usage; a deep under in decisions, the adoption of AHP for this ship's hull application may enhance the likelihood of the composite product's success as the establishment of weights for key parameters promises to produce more reliable and accurate results in decisions [35]. Consequently, this work exploits the integration of PROMETHEE and AHP with synergic benefits, to choose appropriate water absorption parameters for natural particulate composites in ship's hull applications. In this work, the analyzed ship's hull is represented in Figure 1. By the PROMETHEE approach, the water absorption parameters to be chosen are labelled as initial weight (A), final weight (B), length (C), thickness (D) and time (E). It is essential standing and appraisal of these key water absorption parameters is essential.

\section{METHOD}

Procedure for the PROMETHEE method [26-28]. In this paper, attention was focused on dual filled composites, which are more competitive than single filled composites. However, the challenge faced is that they are hydrophilic and this would minimise the material properties and consequently limiting their competitiveness when weighted against the synthetic options. Thus, a deep understanding of the parameters of water absorption was launched by ranking them according to importance. Regarding this, PROMETHEE method is found suitable.

The outranking methods in operations research are procedures that have demonstrated competence to rank activities in order of importance and PROMETHEE procedure is a member of the family ([36], Brans and Vincke,1985; Brans et al; 1986;). Besides, PROMETHEE can estimate how decision-makers naturally develop their preferences in the face of a multidimensional decision perspective [36-38] further declared that a direct meaning of parameters and sensitivity analysis regarding results are the fundamental attributes of PROMETHEE. [39] and [15] summarized the procedure for evaluating parameters using PROMETHEE along these dimensions, provided herewith:

Step 1: As [15] declared, He point-of-commencement to introduce PROMETHEE such as in the evaluation of alternative parameters of the water absorption process is to establish the deviations two options at a time, for all the possible options in the analysis. The outcome is to construct a difference matrix from the matrix containing the actual data. To obtain this, compare the pairs of elements (pairwise subtraction) for all the entries, ensuring that all available combinations for each criterion are made [39].

Step 2: The choice of an appropriate preference function is the next step ([15]. Here a preference function stated as $\mathrm{P}(\mathrm{a}, \mathrm{b})$ is constructed. The symbols $\mathrm{a}$ and $\mathrm{b}$ are the compared elements of the matrix [39]. A final 
matrix is then obtained, referred to as the preference index matrix [39].

Step 3: Compute the preference index termed "global" such that all the preference indices for each parameter and each object is known.

Step 4: Sum up all the global indices to obtain the positive $\left(\phi^{+}\right)$and negative $\left(\phi^{-}\right)$outranking flows. The positive outranking flow establishes how the activities/actions outrank all others. However, its negative outranking flow determines how the activities/actions are outperformed by the compared elements.

Step 5: Consider the set of rules described in [40] and compare the outranking flows pairwise by referring to the rules. The rules in question yield three different outcomes; this yield the poetical pre-order of the objects defined as ranking by PROMETHEE 1 . The first outcome states that an action is approved against another. The second states that no differences occur when two actions are not comparable.

Step 6: Compute the net outranking flow, which is expressed by the symbols $\phi=\phi^{+}-\phi^{-}$. Notice that this omits the rule stated as the third outcome in step 5. Express the outcome in a uni-dimensional ranking, referred to as PROMETHEE II. While it is easier to apply PROMETHEE II, [39] continued that some information may be lost while processing it. This lost information may, however, be kept while applying the partial ranking in PROMETHEE I. Here, options that may not be compared are revealed.

\section{RESULTS AND DISCUSSION}

The objective of the paper is to select the water absorption process parameters using the PROMETHEE multi-criteria model. Water absorption exists in composites within build characteristics of the composite having countermeasures to stop it from being water flooded. There are also several kinds of preventive approaches, such as surface coating to confront water from being associated. However, the choice of an appropriate approach for water absorption prevention depends on several measures. These may include the life expectancy needed from the work material, the application type for the work material, the work material's properties and the characteristics exhibited by the work material during testing. The life expecting aspect interfaces with the life cycle design aspect of the work material and can be dealt with from environmental sustainability in design perspective. Material properties have been addressed in the literature by analyzing the microstructures of material samples. Tensile, formability test, the fire test, commotion test and other related tests have been used to establish the water absorption properties of the work material.

For application type, light water interactions with the material medium and high volume of water interactions with the work material have been used in judgment. However, the characterization of the material, as revealed in [4-7] have been recognized as a reliable approach to testing the water absorption of work materials. Nonetheless, selection has not been rigorously reported in the literature. In this paper, the PROMETHEE multi-criteria is used to obtain the final ranking of the parameters that dictate the quality of water-resistance of a work material subjected to water absorption. From the foregoing, there is no single parameter to ascertain a good for water absorption. From the foregoing, there is no single parameter to ascertain a good choice for water Absorption preventive measures. Therefore, there is a need to establish an importance sale for the parameters involved in water absorption experiments drawing the experimental data from the literature.

Table 2 is the Taguchi response table obtained in [41] and serves as the basis to analyse this work on the PROMETHEE method. This becomes the design table for the PROMETHEE method. In the original table, the meaning of A, B, C, D and E are the final weight, initial weight, Length, thickness and time, respectively. This becomes the design table for PROMETHEE.

TABLE 2

TAGUCHI S/N RATIOS RESPONSE TABLE FOR WATER ABSORPTION OF DUAL-FILLER COMPOSITE [41]

\begin{tabular}{clllll}
\hline Level & \multicolumn{1}{c}{$\mathbf{A}$} & \multicolumn{1}{c}{$\mathbf{B}$} & \multicolumn{1}{c}{$\mathbf{C}$} & \multicolumn{1}{c}{$\mathbf{D}$} & \multicolumn{1}{c}{$\mathbf{E}$} \\
\hline 1 & $*-30.7422$ & -30.7418 & -30.7096 & -30.7455 & $*-30.2670$ \\
2 & -30.7435 & -30.7468 & -30.7707 & -30.7443 & -30.6012 \\
3 & -30.7431 & -30.7438 & $*-30.7071$ & -30.7419 & -30.9083 \\
4 & -30.7431 & $-* 30.7397$ & -30.7847 & $*-30.7403$ & -31.1955 \\
\hline
\end{tabular}

*optimal level

Table 3 illustrates the attributes of the design regarding low and high. To obtain this, the research observes each lend and picks the lowest and highest values, accordingly. For instance, at level 1, the lowest value is 30.7435 while the highest value is -30.7422 .

TABLE 3

ATTRIBUTES FOR DESIGN

\begin{tabular}{lccc}
\hline & Name & Low & High \\
\cline { 2 - 4 } Factor 1 & A & -30.7435 & -30.7422 \\
Factor 2 & B & -30.7468 & -30.7397 \\
Factor 3 & C & -30.7847 & -30.7071 \\
Factor 4 & D & -30.7455 & -30.7403 \\
Factor 5 & E & -31.1955 & -30.2670 \\
\hline
\end{tabular}


Other values are extracted from the original table accordingly. The next stage is to determine the weights of the attributes. In the present work, the analytical hierarchy process (AHP) was used. Besides, in the determination of the final ranks (net outflow quantities) for the application of PROMETHEE to the problem of water absorption process evaluation, it is a requirement to define a set of weights as inputs to the solution procedure. Guided by the knowledge that the analytical hierarchy process (AHP) is a classical approach with proven acceptability in engineering problems, it was thought to be suitable for use as a starting weight determination factor. AHP has a robust structure and found to be easily adaptable to problems. In this context, the AHP was applied to the response table developed by [41] on the original thermoset polymer composite problem.

The surface treatment is an effective method in tackling the concerns regarding the water-resistance of polymer composites. However, the performance of the various water absorption parameters of thermoset polymer composites concerning ranking and selection of the best parameters is not well understood. In this paper, the authors evaluated the water absorption parameters of a thermoset polymer composite using the PROMETHEE method. The significance of this research is to develop an alternative approach to the experience and initiation usage of the fabrication and design engineer in an attempt to produce a thermoset polymer compost of high structural integrity. The use of the PROMETHEE method is to replace the present approach and reduce errors in decision making when fabricating composites for structural purposes. The challenge is to enhance the chances of selecting the best parameter from the group compared with an arbitrary choice of parameters. Hence, in this work, an attempt was made to select the most influential parameters of the water absorption process using the PROMETHEE method with data obtained from the thermoset polymer composted literature.

\section{AHP procedure}

\section{A. Step 1: Attribute design}

To establish the weights of the parameters of concern in this work, the Analytic Hierarchy Process (AHP) was used to map weighted values to the various parameters, which are five parameters. Pair-wise comparison matrix is used to ascertain the comparative importance of various characteristics or parameters regarding the outcome [34], [42-44]. It is achieved using the scale of relative importance. The AHP has the merit of simplicity and robustness. The subsections of the AHP include the development of the pairwise comparison matrix. This serves the purpose to ascertain the comparative importance of the attributes of the water absorption parameters and the response is taken into account. This leads the researcher to the scale of comparative necessity. This scale is the original design by Saaty (1980) and it consists of issues to consider to judge the placement of any of the water absorption parameters over the other. Referred to as Saaty's (1980) importance scale, the six elements contained therein are disruptions and a crisp numeric number assigned in from of it.
The scale of relative importance:

Equal importance 1

Moderate importance 3

Strong importance $\quad 5$

Very strong importance $\quad 7$

Extreme importance $\quad 9$

Intermediate values $\quad 2,4,6,8$.

Values for inverse comparisons 1/3, 1/5, 1/7, 1/9

There are seven items on the list. Usually, the researcher judges two parameters at a time to establish which one is more important than the other. Consider items $\mathrm{A}$ and $\mathrm{B}$, which are the final weight and initial weight of the. It is asked "which one is more important? Here, the researcher acts as an expert and uses his/her knowledge to answer the question. In more robust designs, the researcher may gather several experts and through a questionnaire, assemble them in a group and ask the various questions. The outcome of such a group will be averaged. For more robust structuring, a Delphi making is made in a structured manner, from the literature review; very few authors have applied multicriteria methods to solve water absorption problem. There is no single report available on PROMETHEE's application in the area. Being faced by this paucity of knowledge and experts in the area of this research and in the local environment where this study was conducted, it is thought that the researcher could utilise experience to address the questions. So judgement was made by the researcher to develop the pairwise comparison matrix for use in the present study. Furthermore, recall the earlier discussion on the evaluation based on the first item, 'Equal Importance". This is like saying a 50\% - 50\% equal chance on the sides of the two parameters, final weight and initial weight. If the researcher feels otherwise the next item is checked "Moderate Importance". It is similar to describing either factor as being $60 \%$ in value and the other as $40 \%$ in values. Furthermore, for "Strong Importance", it is like 70\% in value for one parameter and 30\% in value for the other parameter. Very strong importance may be interpreted as $80 \%$ value for a parameter while the other value is $20 \%$ in value. Besides, "Extreme Importance" may mean that a factor has $90 \%$ value while the other has $10 \%$ vlaue. The sixth item, "Intermediate Values" describes the midway for the above decryptions. The midway values are 2, 4, 6, and 8. Take " 2 " for instance; it is the midway between "Equal Importance" and "Moderate Importance," which were assigned 50 and $60 \%$ as the upper values and 40 and $50 \%$ for the lower values. In reality, it is the midway values of about $55 \%$ for the upper value and about $45 \%$ for the lower value. The idea of this analysis is followed through for all the intermediate values. The seventh item, "Values for inverse comparisons: $1 / 3,1 / 5,1 / 7$ and 1/9 are the inverse of the original scale of "Equal importance", ... "Extreme Importance". It should be noted here that the percentages stated above are for illustrative purposes and not those assigned by Saaty (1980) originally. However, they could be of assistance to understand the idea of this study. 
International Journal of Marine Engineering Innovation and Research, Vol. 5(4), Dec. 2020. 206-215 (pISSN: 2541-5972, eISSN: 2548-1479)

\section{B. Step 2: Pair-wise comparison}

The scale of relative importance of the criteria

$\begin{array}{lll}\mathrm{C} & = & 7 \\ \mathrm{D} & = & 5 \\ \mathrm{E} & = & 9\end{array}$

$\begin{array}{lll}\mathrm{A} & = & 3 \\ \mathrm{~B} & = & 3\end{array}$

TABLE 4.

PAIR-WISE COMPARISON MATRIX

\begin{tabular}{lccccc}
\hline & $\mathbf{A ~ ( 3 )}$ & $\mathbf{B ~ ( 3 )}$ & $\mathbf{C ~ ( 7 )}$ & $\mathbf{D}(\mathbf{5})$ & $\mathbf{E}(\mathbf{9})$ \\
\cline { 2 - 6 } A (3) & 1 & 1 & 0.43 & 0.6 & 0.33 \\
B (3) & 1 & 1 & 0.43 & 0.6 & 0.33 \\
C (7) & 2.33 & 2.33 & 1 & 1.4 & 0.78 \\
D (5) & 1.67 & 1.67 & 0.71 & 1 & 0.56 \\
E (9) & 3 & 3 & 1.29 & 1.8 & 1 \\
Total & 9 & 9 & 3.86 & 5.4 & 3 \\
\hline
\end{tabular}

Pairwise compares is the procedure used to weigh paired entities against each other, to pronounce which of the entities is the favourite (Table 4). The choice is motivated by the application considered. The choice is favoured by the element that displays a larger amount of particular quantitative property. However, the two entities may be identical and equally favoured by the choice. PROMETHEE utilises pairwise comparison method to solve problems. In the water absorption process parametric choice, five options are considered in the case analysed, including final weight, initial weight, thickness, length and time. The question that the composite designer and engineer falls is how do I decide on the best parameter? Do I pick a time at the expense of thickness? The composite designers may be more interested in thickness more than anything else. It is thought that the philosophy in design is moving towards lightweight structures to justify his/her bias for thickness. Conversely, the fabrication engineer may be interested in time, to decide on how long the period of the composite is affected by water while in use.

In pairwise comparison, each parameter is matched with every other parameter, but matching is done with only one parameter at a time. If the parameter is favoured, that is, having a one-to-one win, a higher value of scale is given to it compared with the parameter that it defeats. If the reverse is the case, the parameter losses and the compared one is preferred. A third case is when an equal weight is given to the two parameters considered. These are called a tie and the point is shared equally or as in the case of analytical hierarchy process, the scale of importance assigns a value of 1 to the relationship. The value for each decision is put in a square in the matrix. In the psychology literature, pairwise comparison has been known for several decades. The credit of introducing the paired comparison concept is given to L.L. Thurston that utilized a scientific method which engaged pairwise comparison to measure quantities in 1927. In his words, the best description of the idea was under the law of comparative judgment. This innovator, who was known as a psychometrician associated the pairwise comparison, often called paired comparison, to psychophysical theory and then employed the approach to ordering items regarding a measure, for instance, importance or preference. However, an interval-kind scale was applied.

\section{Step 3: Obtaining the normalized pair-wise comparison matrix \\ The normalized pair-wise comparison matrix is} obtained by dividing all the element of the column with the sum of the column (Table 5). The criteria and their weighted values are then established (Table 6).

TABLE 5.

THE NORMALIZED PAIR-WISE COMPARISON MATRIX

\begin{tabular}{lcccccc}
\hline & A (3) & B (3) & C (7) & D (5) & E (9) & Critical Weight \\
\cline { 2 - 6 } A (3) & 0.11 & 0.11 & 0.11 & 0.11 & 0.11 & 0.55 \\
B (3) & 0.11 & 0.11 & 0.11 & 0.11 & 0.11 & 0.55 \\
C (7) & 0.26 & 0.26 & 0.26 & 0.26 & 0.26 & 1.3 \\
D (5) & 0.19 & 0.19 & 0.18 & 0.19 & 0.19 & 0.94 \\
E (9) & 0.33 & 0.33 & 0.33 & 0.33 & 0.33 & 1.65 \\
\hline
\end{tabular}

TABLE 6.

CRITERIA AND THEIR WEIGHTED VALUES

\begin{tabular}{lccccc}
\hline $\begin{array}{l}\text { weightage } \rightarrow \\
\begin{array}{c}\text { Level } \\
\downarrow\end{array}\end{array}$ & $\mathbf{0 . 5 5}$ & $\mathbf{0 . 5 5}$ & $\mathbf{1 . 3}$ & $\mathbf{0 . 9 4}$ & $\mathbf{1 . 6 5}$ \\
& $\mathbf{A}$ & $\mathbf{B}$ & $\mathbf{C}$ & $\mathbf{D}$ & $\mathbf{E}$ \\
\hline 1 & & & & & \\
2 & -30.7422 & -30.7418 & -30.7096 & -30.7455 & -30.2670 \\
3 & -30.7435 & -30.7468 & -30.7707 & -30.7443 & -30.6012 \\
4 & -30.7431 & -30.7438 & -30.7071 & -30.7419 & -30.9083 \\
\hline
\end{tabular}


D. Step 4: Normalization of the evaluated matrix (decision matrix)

The normalization is done using the following formulae (Table 6):

For the non-beneficial criteria (factors), the decision matrix is given by:

$$
R_{i j}=\frac{\left[\operatorname{Max}\left(x_{i j}\right)-x_{i j}\right]}{\left[\operatorname{Max}\left(x_{i j}\right)-\operatorname{Min}\left(x_{i j}\right)\right]}
$$

where $\mathrm{i}=1,2,3,4,5$ and $\mathrm{j}=1,2,3,4,5$

Regarding A (initial weight) (Table 7):
Maximum value is -30.7422 , minimum value $=-30.7435$ while max value - min value $=0.0013$ and $R_{11}$ becomes 0. Similarly, $R_{12}, R_{13}, R_{14}$, become $1,0.692$ and 0.692 , respectively.

Regarding B (final weight): $R_{21}, R_{22}, R_{23}, R_{24}$, become $0.296,1,0.577$ and 0 , respectively.

Regarding C (length): $R_{31}, R_{32}, R_{33}, R_{34}$, become 0.003 , $0.820,0$ and 1 , respectively.

Regarding D (thickness): $R_{41}, R_{42}, R_{43}, R_{44}$, become 1 , $0.769,0.308$ and 0 , respectively.

Regarding E (time): $R_{51}, R_{52}, R_{53}, R_{54}$, become $0,0.360$, 0.691 and 1 , respectively.

TABLE 7.

THE NORMALIZED MATRIX

\begin{tabular}{cccccc}
\hline Attributes & A & B & C & D & E \\
\hline 1 & 0 & 0.296 & 0.003 & 1 & 0 \\
2 & 1 & 1 & 0.820 & 0.769 & 0.360 \\
3 & 0.692 & 0.577 & 0 & 0.308 & 0.691 \\
4 & 0.692 & 0 & 1 & 0 & 1 \\
\hline
\end{tabular}

This is done using the expression

PROMETHEE procedure [26-28]

Step 1: Evaluative difference of $i^{\text {th }}$ alternatives with respect to other alternatives

The difference of each alternative with respect to other alternatives in the same criteria/attributes is evaluated (Table 8).

TABLE 8. COMPUTATIONS BASED ON NORMALIZED MATRIX

\begin{tabular}{crrrrr}
\hline Attributes & $\mathrm{A}$ & $\mathrm{B}$ & $\mathrm{C}$ & $\mathrm{D}$ & \multicolumn{1}{c}{$\mathrm{E}$} \\
\hline 1 & 0 & 0.296 & 0.003 & 1 & 0 \\
3 & 1 & 1 & 0.820 & 0.769 & 0.360 \\
4 & 0.692 & 0.577 & 0 & 0.308 & 0.691 \\
$\mathrm{n}$ & 0.692 & 0 & 1 & 0 & 1 \\
\hline $\mathrm{D}\left(\mathrm{R}_{1}-\mathrm{R}_{2}\right) / 5$ & -1 & -0.708 & -0.817 & 0.231 & -0.36 \\
$\mathrm{D}\left(\mathrm{R}_{1}-\mathrm{R}_{3}\right) / 5$ & -0.692 & -0.285 & 0.003 & 0.692 & -0.691 \\
$\mathrm{D}\left(\mathrm{R}_{1}-\mathrm{R}_{4}\right) / 5$ & -0.692 & 0.292 & -0.997 & 1 & -1 \\
$\mathrm{D}\left(\mathrm{R}_{2}-\mathrm{R}_{1}\right) / 5$ & 1 & 0.708 & 0.817 & -0.231 & 0.36 \\
$\mathrm{D}\left(\mathrm{R}_{2}-\mathrm{R}_{3}\right) / 5$ & 0.308 & 0.423 & 0.82 & 0.461 & -0.331 \\
$\mathrm{D}\left(\mathrm{R}_{2}-\mathrm{R}_{3}\right) / 5$ & 0.308 & 1.18 & -0.18 & 0.769 & -0.64 \\
$\mathrm{D}\left(\mathrm{R}_{3}-\mathrm{R}_{1}\right) / 5$ & 0.692 & 0.285 & -0.003 & -0.692 & 0.691 \\
$\mathrm{D}\left(\mathrm{R}_{3}-\mathrm{R}_{2}\right) / 5$ & -0.308 & -0.423 & -0.82 & -0.461 & 0.331 \\
$\mathrm{D}\left(\mathrm{R}_{3}-\mathrm{R}_{4}\right) / 5$ & 0 & 0.577 & -1 & 0.308 & -0.309 \\
$\mathrm{D}\left(\mathrm{R}_{4}-\mathrm{R}_{1}\right) / 5$ & 0.692 & -0.292 & 0.997 & -1 & 1 \\
$\mathrm{D}\left(\mathrm{R}_{4}-\mathrm{R}_{2}\right) / 5$ & -0.308 & -1 & 0.18 & -0.769 & 0.64 \\
$\mathrm{D}\left(\mathrm{R}_{4}-\mathrm{R}_{3}\right) / 5$ & 0 & -0.577 & 1 & -0.308 & 0.309 \\
\hline
\end{tabular}

Steps 2 and 3: Calculation of the preference function (Table 9)

The preference function is calculated using the given formulas:

1. $P_{j}(\mathrm{a}, \mathrm{b})=0$. If, $\mathrm{R}_{\mathrm{aj}} \leq \mathrm{R}_{\mathrm{bj}} \rightarrow \mathrm{D}\left(\mathrm{R}_{\mathrm{a}}-\mathrm{R}_{\mathrm{b}}\right) \leq 0$

That is, if the difference between two alternatives as calculated in Table 8 is less than or equal to zero: then that value automatically becomes zero.

2. $P_{j}(\mathrm{a}, \mathrm{b})=\left(\mathrm{R}_{\mathrm{aj}}-\mathrm{R}_{\mathrm{bj}}\right)$, if $\mathrm{R}_{\mathrm{aj}}>\mathrm{R}_{\mathrm{bj}} \rightarrow \mathrm{D}(\mathrm{Ra}-\mathrm{Rb})$ $>0$.

That is if the difference between one alternative with respect to others are greater than zero; then it retains its value.

TABLE 9.

THE PREFERENCE FUNCTION, $P_{J}(A, B)$

\begin{tabular}{lrrrrr}
\hline Attributes & \multicolumn{1}{c}{ A } & \multicolumn{1}{c}{ B } & \multicolumn{1}{c}{ C } & \multicolumn{1}{c}{ D } & \multicolumn{1}{c}{ E } \\
\hline $\mathrm{P}\left(\mathrm{R}_{1}-\mathrm{R}_{2}\right) / 5$ & 0 & 0 & 0 & 0.231 & 0 \\
$\mathrm{P}\left(\mathrm{R}_{1}-\mathrm{R}_{3}\right) / 5$ & 0 & 0 & 0.003 & 0.692 & 0 \\
$\mathrm{P}\left(\mathrm{R}_{1}-\mathrm{R}_{4}\right) / 5$ & 0 & 0.292 & 0 & 1 & 0 \\
$\mathrm{P}\left(\mathrm{R}_{2}-\mathrm{R}_{1}\right) / 5$ & 1 & 0.708 & 0.817 & 0 & 0.36 \\
$\mathrm{P}\left(\mathrm{R}_{2}-\mathrm{R}_{3}\right) / 5$ & 0.308 & 0.423 & 0.82 & 0.461 & 0 \\
\hline
\end{tabular}


International Journal of Marine Engineering Innovation and Research, Vol. 5(4), Dec. 2020. 206-215 (pISSN: 2541-5972, eISSN: 2548-1479)

\begin{tabular}{lrrrrr}
\hline $\mathrm{P}\left(\mathrm{R}_{2}-\mathrm{R}_{3}\right) / 5$ & 0.308 & 1 & 0 & 0.769 & 0 \\
$\mathrm{P}\left(\mathrm{R}_{3}-\mathrm{R}_{1}\right) / 5$ & 0.692 & 0.285 & 0 & 0 & 0.691 \\
$\mathrm{P}\left(\mathrm{R}_{3}-\mathrm{R}_{2}\right) / 5$ & 0 & 0 & 0 & 0 & 0.331 \\
$\mathrm{P}\left(\mathrm{R}_{3}-\mathrm{R}_{4}\right) / 5$ & 0 & 0.577 & 0 & 0.308 & 0 \\
$\mathrm{P}\left(\mathrm{R}_{4}-\mathrm{R}_{1}\right) / 5$ & 0.692 & 0 & 0.997 & 0 & 1 \\
$\mathrm{P}\left(\mathrm{R}_{4}-\mathrm{R}_{2}\right) / 5$ & 0 & 0 & 0.18 & 0 & 0.64 \\
$\mathrm{P}\left(\mathrm{R}_{4}-\mathrm{R}_{3}\right) / 5$ & 0 & 0 & 1 & 0 & 0.309 \\
\hline
\end{tabular}

Step 4: Calculate the aggregated preference function (Table 10)

This is done by giving consideration to the criteria weights using the formula:

$\Pi(a, b)=\left[W_{j} P_{j}(a, b)\right] / \Sigma W_{j}$
(2)

where $\Pi(\mathrm{a}, \mathrm{b})$ is the aggregated preference function, $W_{j}$ is the criteria weight, and $P_{j}(a, b)$ is the preference function

Notice that

$P_{j}(a, b)=P\left(R_{a j}-R_{b j}\right)$

Summation of weight, $\Sigma W_{j}=0.55+0.55+1.3+0.94$

$+1.65=4.99 \approx 5$

TABLE 10.

AGGREGATED PREFERENCE FUNCTION

\begin{tabular}{lrrrrrr}
\hline Attributes & $\mathbf{A}$ & $\mathbf{B}$ & $\mathbf{C}$ & $\mathbf{D}$ & $\mathbf{E}$ & $\prod(A, B)$ \\
\hline Weights & 0.55 & 0.55 & 1.3 & 0.94 & 1.65 & \\
$W_{j}^{*} \mathrm{P}\left(\mathrm{R}_{1}-\mathrm{R}_{2}\right) / 5$ & 0 & 0 & 0 & 0.0434 & 0 & 0.0434 \\
$W_{j}^{*} \mathrm{P}\left(\mathrm{R}_{1}-\mathrm{R}_{3}\right) / 5$ & 0 & 0 & 0.0008 & 0.1301 & 0 & 0.1309 \\
$W_{j}^{*} \mathrm{P}\left(\mathrm{R}_{1}-\mathrm{R}_{4}\right) / 5$ & 0 & 0.0321 & 0 & 0.1880 & 0 & 0.2201 \\
$W_{j}^{*} \mathrm{P}\left(\mathrm{R}_{2}-\mathrm{R}_{1}\right) / 5$ & 0.11 & 0.0779 & 0.2132 & 0 & 0.1188 & 0.5199 \\
$W_{j}^{*} \mathrm{P}\left(\mathrm{R}_{2}-\mathrm{R}_{3}\right) / 5$ & 0.0339 & 0.0465 & 0.2132 & 0.0867 & 0 & 0.3803 \\
$W_{j}^{*} \mathrm{P}\left(\mathrm{R}_{2}-\mathrm{R}_{3}\right) / 5$ & 0.0339 & 0.11 & 0 & 0.1446 & 0 & 0.2885 \\
$W_{j}^{*} \mathrm{P}\left(\mathrm{R}_{3}-\mathrm{R}_{1}\right) / 5$ & 0.0761 & 0.0314 & 0 & 0 & 0.2280 & 0.3355 \\
$W_{j}^{*} \mathrm{P}\left(\mathrm{R}_{3}-\mathrm{R}_{2}\right) / 5$ & 0 & 0 & 0 & 0 & 0.1092 & 0.1092 \\
$W_{j}^{*} \mathrm{P}\left(\mathrm{R}_{3}-\mathrm{R}_{4}\right) / 5$ & 0 & 0.0635 & 0 & 0.0579 & 0 & 0.1214 \\
$W_{j}^{*} \mathrm{P}\left(\mathrm{R}_{4}-\mathrm{R}_{1}\right) / 5$ & 0.0761 & 0 & 0.2592 & 0 & 0.3300 & 0.6653 \\
$W_{j}^{*} \mathrm{P}\left(\mathrm{R}_{4}-\mathrm{R}_{2}\right) / 5$ & 0 & 0 & 0.0468 & 0 & 0.2112 & 0.2580 \\
$W_{j}^{*} \mathrm{P}\left(\mathrm{R}_{4}-\mathrm{R}_{3}\right) / 5$ & 0 & 0 & 0.2600 & 0 & 0.1020 & 0.3620 \\
\hline
\end{tabular}

$\phi^{-}=\frac{1}{C-1} \sum \pi(b, a) ;(a \neq b)$

Step 4 and 5: Determination of leaving and entering outranking flows

A. Leaving (positive) flow for $a^{\text {th }}$ alternative,

$$
\phi^{+}=\frac{1}{C-1} \sum \pi(b, a) ;(a \neq b)
$$

where $\mathrm{C}$, number of alternatives, is 4

B. Entering (negative) flow for $a^{\text {th }}$ alternative;

OUTRANKING FLOW

\begin{tabular}{|c|c|c|c|c|c|c|}
\hline $\begin{array}{l}\text { Aggregate preference } \\
\text { function }\end{array}$ & $\mathbf{A}$ & B & $\mathrm{C}$ & D & $\mathbf{E}$ & $\begin{array}{c}\Phi^{+} \\
\text {Leaving Flow }\end{array}$ \\
\hline $\mathrm{A}$ & - & - & & & & \\
\hline B & - & - & 0.04342 & 0.1309 & 0.2201 & 0.39442 \\
\hline $\mathrm{C}$ & - & - & 0.5199 & 0.3803 & 0.2885 & $0.8709 *$ \\
\hline $\mathrm{D}$ & - & & 0.3355 & 0.1092 & 0.1214 & $0.5661 *$ \\
\hline $\mathrm{E}$ & - & - & 0.6653 & 0.1092 & 0.1214 & $0.8959 *$ \\
\hline$\Phi$-Entering Flow & & & $1.5641 *$ & $0.7296 *$ & $0.7514 *$ & \\
\hline
\end{tabular}

Step 6: Net outranking flow of each alternative

The net outranking flow for each alternative is calculated

By forming a matrix of order corresponding to the number of alternatives (Table 11)

Hence, restricting the Aggregated Preference Function from $\mathrm{R}_{1}$ to $\mathrm{R}_{2}$. by (Table 12):

TABLE 12.

NET OUTRANKING

\begin{tabular}{lcccc}
\hline & $\phi^{+}(a)$ & $\phi^{-}(a)$ & $\phi(a)$ & Rank \\
\cline { 2 - 5 } $\mathrm{C}$ & 0.8709 & 1.5641 & $\mathbf{- 0 . 6 9 3 2}$ & 3 \\
$\mathrm{D}$ & 0.5661 & 0.7296 & $\mathbf{- 0 . 1 6 3 5}$ & 2 \\
$\mathrm{E}$ & 0.8959 & 0.7514 & $\mathbf{0 . 1 4 4 5}$ & 1 \\
\hline
\end{tabular}


PROMETHEE is demonstrated in this paper as an approach to assigning priorities to several parameters in the water absorption process. The method was chosen to understand the designer's characteristics and values the fabricator places on each parameter in the water absorption process. The PROMETHEE approach also aids in understanding the decision capabilities of the designer and fabricator. In reality, there are several parameters to choose from and the designer and fabricator of composites are often overwhelmed to rank the parameters. The use of intuition and experience of the designer and fabricator is often made. However, this often fails and the ranking method of PROMETHEE is suitable for use. The reality is that the use of PROMETHEE method is a scientific tool to overcome the limitation of the designers and fabricators of thermoset polymers composites. They are limited in that their human ability cannot rank the various parameters regarding their actual values.

\section{CONCLUSION}

Using PROMETHEE based on AHP to establish weights, time was chosen as the most important parameter in the water absorption process of a natural particulate composite compared with four other probable parameters in compromise solution satisfaction. The integration of PROMETHEE and AHP proves that the approach yields a superior level of confidence to the composite developer. This may be applied in similar water absorption process parametric selection in involving polymer composites by deploying the PROMETHEE method as it is innovative and scientific. It is envisaged that this work contributes substantially to the understanding of composite development research and discussions surrounding the importance of water absorption parameters to select composites for applications involving the hull of a ship. It is part of a requirement for effective design of robust water-resistant composites for ship hulls. Furthermore, this paper is a valuable resource for researches in the natural particulate reinforced thermoset polymer composites in marine applications.

This study provides a detailed analysis of how to select important water absorption parameters using PROMETHEE method and verifying it with experimented data. It was decided that the heading parameter is time, followed by thickness and length. In illuminating the findings, it is anticipated that subjective evaluation of composites by composite developers and decision-makers might be eradicated. Though this study acknowledges that deployment of multicriteria analysis to water absorption studies in composite research has great potentials to influence the development of robust water-resistant thermoset composites for the ship's hull, currently, it penetrates merely small aspects. Additional research is warranted if objective criteria selection research is to emerge as a detailed part of the composite developer's practice worldwide.

\section{REFERENCES}

[1] Kumar M., Kumar A., 2020, Application of Reference selection index method in performance-based ranking of ceramic particulate $\left(\mathrm{SiO}_{2} / \mathrm{SiC}\right)$ reinforced AA2024 composite materials, Materials Today: Proceedings, Vol. 27, No.3, pp. 2667-2672

[2] Sheng A., Ren W., Yang Y., Yan D.-X., Li Z.-M., 2020 Multilayer WPU conductive composites with controllable electromagnetic gradient for absorption-dominated electromagnetic interference shielding, Composites Part A: Applied Science and $\begin{array}{llll}\text { Manufacturing, Vol. } & 129, & \text { Article } & 105692 .\end{array}$ https://doi.org/10.1016/j.compositesa.2019.105692

[3] Zhang J., Cheng X., Cheng Y., Guo X., Yang L. 2020. Effect of over-ply on moisture absorption behavior of scarf-repaired composite laminate, International Journal of Adhesion and Adhesives, $\begin{array}{llll}\text { Vol. } & 102, & \text { Article } & 102683\end{array}$ https://doi.org/10.1016/j.ijadhadh.2020.102683

[4] Sari N.H., Pruncu C.I., Sapuan S.M., Ilyas R.A., Catur A.D., Suteja S., Sutaryono Y.A., Pullen G. 2020, The effect of water immersion and fibre content on properties of corn husk fibres reinforced thermoset polyester composite, Polymer Testing, In press, Article 106751. https://doi.org/10.1016/j.polymertesting.2020.106751 [5] Oladele I.O., Ajileye J.O., Oke S. R., Daramola O.O., Adewumi O.A. 2020, Thermal and water absorption properties of bio-synthetic hybrid reinforced polypropylene composites, Materials Today: Proceedings, In press, Article. https://doi.org/10.1016/j.matpr.2020.05.580

[6] Imoisili P.E., Jen T.-C. 2020, Mechanical and water absorption behaviour of potassium permanganate $\left(\mathrm{KMnO}_{4}\right)$ treated plantain (Musa Paradisiacal) fibre/epoxy bio-composites, Journal of Materials Research and Technology, Vol. 9, No. 4, pp. 87058713. https://doi.org/10.1016/j.jmrt.2020.05.121

[7] Kusmono, Hestiawan H., Jamasri, 2020, The water absorption, mechanical and thermal properties of chemically treated woven fan palm reinforced polyester composites, Journal of Materials Research and Technology, Vol. 9, No. 3, pp. 4410-4420. https://doi.org/10.1016/j.jmrt.2020.02.065

[8] Singh T., Patnaik A, Chauhan R., 2017, Tribo performance evaluation and optimisation of fibre-reinforced phenolic-based friction composites, in Primary and Secondary Manufacturing of Polymer Matrix composites, Debnath K., Singh I., Chapter S., 11p., CRC Press, DOI: $10.1201 / 9781351228466-9$

[9] Shaharuzaman M.A., Sapuan S.M., Mansor M.R., Zuhuri M.Y.M., 2019 Decision support strategy in selecting natural fibre materials for automotive side-door impact beam composites, Journal of Renewable Materials, Vol. 7, No. 10, pp. 997-1010, DOI 10.32604/jrm. 2019. 07529 .

[10] Ishak N.M., Malingam S.D., Mansor M.R., 2016, Selection of natural fiber reinforced composites using fuzzy VIKOR for car front hood, International Journal of Materials and Product Technology, Vol. 53, no. 3-1, pp. 267-285.

[11] Karakus K., Aydemir D., Oztel A., AAA, 2017, Nanoboron nitride-filled heat-treated wood polymer nano-composites: Comparison of different multi-criteria decision-making models to predict optimum properties of the nanocomposites, DOI: 10.1177/0021998317699984

[12] Karthick R., Anbumalar V., Sutharson B., 2018, Comparative analysis of mechanical and water absorption behaviour of jute/glass fibre reinforced epoxy and polyester hybrid composites, International Journal of Materials Engineering Innovation, Vol.9, No.2, pp.82-93

[13] Jumadi M.T., Mansor M.R., Mustafa Z. 2018, Influence of water absorptivity on kenaf fibre reinforced recycled-polymer composite properties, Progress in Industrial Ecology, An International Journal, Vol.12, No.3, pp.220 - 233

[14] Saxena M., Gupta M.K. 2018, Mechanical, thermal, and water absorption properties of hybrid wood composites, Proceedings of the Institution of Mechanical Engineers, Part L: Journal of Materials: Design and Applications, Vol. 233, No. 9, pp. 1914-1922

[15] Makan A. and Fadili A; 2020, sustainability assessment of healthcare waste treatment systems using surrogate weights and PROMETHEE method, Waste Management and Research, pp.1-10, DOI: $10.1177 / 0734242 \times 20947162$

[16] Coban A, Ertis IF and Cavdaroglu NA, 2018, Municipal solid waste management via multi-criteria decision making methods: A case study in Istanbul, Turkey. Journal of Cleaner Production, Vol. 180, pp. 159-167.

[17] Herva M and Roca E 2013, Ranking municipal solid waste treatment alternatives based on ecological footprint and multi-criteria analysis. Ecological Indicators, Vol. 25, pp. 77-84.

[18] Huang IB, Keisler J and Linkov I, 2011, Multi-criteria decision analysis in environmental sciences: ten years of applications and trends. Science of the Total Environment, Vol. 409, pp. 3578-3594. 
[19] Pires A, Martinho G, Rodrigues S, et al. 2019, Multi-criteria decision making in waste collection to reach sustainable waste management. In: Sustainable Solid Waste Collection and Management. Cham: Springer, pp. 239-260.

[20] Santos SM, Silva MM, Melo RM, et al. 2017, Multi-criteria analysis for municipal solid waste management in a Brazilian metropolitan area. Environmental Monitoring and Assessment, Vol. 189 , p. 561

[21] Soltani A., Hewage K., Reza B., Sadiq R. 2015, Multiple stakeholders in multicriteria decision-making in the context of municipal solid waste management: A review. Waste Management, Vol. 35, pp. 318-328.

[22] Patnaik P. K., Mishra S.K. and Ashish A.T., 2020. Ranking of fiber reinforced composite materials using PSI and PROMETHEE method, 2020 International Conference on Computer Science, Engineering and Applications (ICCSEA), Gunupur, India, 2020, pp. 15, doi: 10.1109/ICCSEA49143.2020.9132853.

[23] Pradhan M.K., Singh B., 2019, Machinability and multiresponse optimisation of EDM OF AI7075/Sic/WS 2 hybrid composite using the PROMETHEE method, in Kumar K., Davim J.P, Optimisation for Engineering Problems, Wiley Publishers, Chapter 3, pp. 39-62, Wiley Publishers.

[24] Justino Netto, J.M., Ragoni, I.G., Frezzatto Santos, L.E. et al. Selecting low-cost 3D printers using the AHP method: a case study. SN Applied Sciences, Vol. 1, $335 \quad$ (2019). https://doi.org/10.1007/s42452-019-0352-4

[25] Ozdogan, S., Yildizbasi, A. \& Rouyendegh, B.D. Performance evaluation of municipal services with fuzzy multi-criteria decision making approaches: a case study from Turkey. SN Applied Sciences, Vol. 2, 1056 (2020). https://doi.org/10.1007/s42452-0202843-8

[26] Balli, S., Yilmaz, M. 2020. Multi-criteria usability evaluation of symmetric data encryption algorithms in fuzzy environment. SN Applied Sciences, Vol. 2, 1393. https://doi.org/10.1007/s42452-020-3170-9

[27] Banihabib, M.E., Chitsaz, N. \& Randhir, T.O. Noncompensatory decision model for incorporating the sustainable development criteria in flood risk management plans. SN Applied Sciences, Vol. 2, 6 (2020). https://doi.org/10.1007/s42452-019-1695-6 [28] Naresh Babu, M., Anandan, V., Muthukrishnan, N. et al. Evaluation of graphene based nano fluids with minimum quantity lubrication in turning of AISI D3 steel. SN Applied Sciences, Vol. 1, 1202 (2019). https://doi.org/10.1007/s42452-019-1182-0

[29] Yıldızbaşı, A., Ünlü, V. 2020, Performance evaluation of SMEs towards Industry 4.0 using fuzzy group decision making methods. SN Applied Sciences Vol. 2, 355. https://doi.org/10.1007/s42452-020-2085-9

[30] Aydemir D., Alsan M., Altuntas E. \& Ozte A. 2019, Mechanical, thermal and morphological properties of heat-treated wood-polypropylene composites and comparison of the composites with PROMETHEE method, Plastics, Rubber and Composites: Macromolecular Engineering, Vol.48, No. 9, pp. 389-400. https://doi.org/10.1080/14658011.2019.1638132

[31] Gul M., Celik E., Gumus A.T., Guneri A.F. 2018. A fuzzy logic based PROMETHEE method for material selection problems, Beni-Suef University Journal of Basic and Applied Sciences, Vol. 7, No. 1, pp. pp. 68-79. https://doi.org/10.1016/j.bjbas.2017.07.002

[32] Roseline S., Paramasivan V., Anandhakri R., Lakshminarayanan P.R., 2019, Numerical evaluation of zirconium reinforced aluminium matrix composites for sustainable environment, Annals of Operations Research, Vol. 275, No.2, pp.653-667.

[33] Behzadian M., Kazemzadeh R.B., Albadvi A., Aghdasi M. 2010, PROMETHEE: A comprehensive literature review on methodologies and applications, European Journal of Operational Research, Vol. 200, pp.198-215

[34] Song B., Kang S. 2016, A method of assigning weights using a ranking and nonhierarchy comparison, Advances in Decision Sciences, Vol. 1-2, pp. 1-9. DOI: 10.1155/2016/8963214

[35] Ishak N.M., Swakumar D., Mansor M.R., 2017, Thermoplastic matrix selection for fibre metal laminate using fuzzy VIKOR and entropy measure for objective weighting, Journal of
Engineering Science and Technology, Vol. 12, No. 10, pp. 2792 2804.

[36] Schwartz M. and Gothner M; 2009, A multi-dimensional evaluation of the effectiveness of business incubators: An application of the PROMETHEE outranking method, Environment and Planning C: Government and policy, Vol.27, pp.1072-1087

[37] Al-Rashdan D, Al-Kloub B, Dean A, Al-Shemmeri T; 1999 , Environmental impact assessment and ranking the environmental projects in Jordan, European Journal of Operational Research, Vol.118, pp.30-45

[38] Goumas M, Lygeoru v, 2000, An extension of the PROMETHEE method for decision making in fuzzy environment: ranking of alternative energy exploitation projects, European Journal of Operational Research, Vol.123, pp.606-613

[39] Carmody O., Frost R.L., Kristof J., Kokot S., Kloprogge J.T and Mako E., 2006, Modification of kaolinite surfaces through mechanochemical activation with quartz: A diffuse reflectance infrared fourier transform and chemometrics study, Applied Spectroscopy, Vol.60, No.12, pp.1414-1422

[40] Keller H.R., Massart D.L., Brans J.P. 1991. Multicriteria decision making: A case study. Chemometrics and Intelligent Laboratory Systems, Vol. 11, No. 2, pp. 175-189

[41] Ajibade O.A., Agunsoye J.O., Oke S.A., 2019, Optimisation of water absorption parameters of dual-filler filled composites using Taguchi and moderated Taguchi techniques, Kufa Journal of Engineering, Vol. 10, No. 2, pp. 134-151.

[42] Kou G., Ergu D., Lin C. \& Chen Y. 2016, Pairwise comparison matrix in multiple criteria decision making, Technological and Economic Development of Economy, Vol. 22, No. 5, pp. 738-765. doi:10.3846/20294913.2016.1210694

[43] Bozóki S., Fülöp J. 2017, Efficient weight vectors from pairwise comparison matrices, European Journal of Operational Research, 2018, Vol. 264, No. 2, pp.419-427. DOI: 10.1016/j.ejor.2017.06.033

[44] Ramík J. 2020, Pairwise Comparison Matrices in DecisionMaking. In: Pairwise Comparisons Method. Lecture Notes in Economics and Mathematical Systems, vol 690. Springer, Cham. https://doi.org/10.1007/978-3-030-39891-0_2

[45] Aherwar A., Singh T., Singh A., Patnaik A., Fekete G. 2019, Optimum selection of novel developed implant material using hybrid entropy-PROMETHEE approach, Materials Science and Engineering Technology, Vol. 50, No. 10, pp. 1232-1241. https://doi.org/10.1002/mawe.201800088

[46] İç, Y.T., Şimşek, E. Operating window perspective integrated TOPSIS approach for hybrid electrical automobile selection. SN Applied Sciences Vol. 1, $1314 \quad$ (2019). https://doi.org/10.1007/s42452-019-1357-8

[47] Kesharwani, N., Bajpai, S. Batch anaerobic co-digestion of food waste and sludge: a multi criteria decision modelling (MCDM) approach. SN Applied Sciences, Vol. 2, 1467 (2020). https://doi.org/10.1007/s42452-020-03265-1

[48] (Moher), Liberati A, Tel zlaff J, Altman D.G., PRISMA Group, for the PRISMA Group. Preferred reporting items for systematic reviews and mete-analyses the PRIMA statement. PLOS Med, Vol.6, No.7,e1000097)

[49] Oliveira M., Fontes D.B.M.M., Pereira T., 2018, Evaluating vehicle painting plans in an automobile assembly plant using an integrated AHP-PROMETHEE approach, International Transactions in Operational Research, Vol. 25, No. 4, pp. 1383-1406. https://doi.org/10.1111/itor.12179

[50] Sharma, M., Baloni, B.D. 2020, Design optimization of Sshaped compressor transition duct using particle swarm optimization $\begin{array}{llllll}\text { algorithm. SN Applied } & \text { Sciences, } & \text { Vol. 2, } & \end{array}$ https://doi.org/10.1007/s42452-020-1972-4

[51] Wu Y., Liu F., Huang Y., Xu C., Zhang B., Ke Y., Jia W., 2020, A two-stage decision framework for inland nuclear power plant site selection based on GIS and type-2 fuzzy PROMETHEE II: Case study in China, Energy Science and Engineering, Vol. 8, No. 6, pp. 1941-1961. https://doi.org/10.1002/ese3.640 